\title{
Dynamic Behaviour of Flat Slabs
}

\author{
Sheeza Manzoor ${ }^{1}$, Gagan Kumar ${ }^{2}$ \\ ${ }^{1}$ M.Tech Student, Department of Civil Engineering, Shree Siddhivinayak Group of Institutions, Bilaspur, Affiliated to Kurukshetra \\ University, Kurukshetra, Haryana, India \\ ${ }^{2}$ Assistant Professor, Department of Civil Engineering, Shree Siddhivinayak Group of Institutions, Bilaspur, Affiliated to Kurukshetra \\ University, Kurukshetra, Haryana, India
}

\begin{abstract}
The buildings are encountered by earthquake and wind forces throughout their life. These lateral forces produce vibrations in all the elements of the building. To cater the floors of large populated halls like restaurants, concerts, theatres etc, large column spacing is required. Due to the large span, tremendous vibrations are induced in these floors, which are controlled by the use of flat slabs. The amount of vibrations depends upon the material, span, thickness, and damping of the flat slabs. To control these vibrations, parametric investigation is carried out to study the response of flat slab under different exciting/frequencies while changing the end conditions. In this study, optimum parameters are obtained to control the deflections and vibrations of flat slabs in the buildings.
\end{abstract}

Keywords: Damping ratio, Dynamic response, Flat slab, Frequency content, Stiffness

\section{Introduction}

A traditional common practice in construction is to support slab by beam and beam supported by column, this may be called as beam slab load transfer construction technique. As due to this old traditional construction net height of room is reduced. Hence to improve aesthetical and structural aspect of multi storey buildings, shopping malls, offices, warehouses, public community halls etc. are constructed in such a way where the slab is directly supported on the columns. This type of slab is termed as flat slab.

This system is very simple to construct, and is efficient in that it requires the minimum building height for a given number of stories. Unfortunately, earthquake experience has proved that this form of construction is vulnerable to failure, when not designed and detailed properly, in which the thin concrete slab fractures around the supporting columns and drops downward, leading potentially to a complete progressive collapse of a building as one floor cascades down onto the floors below.

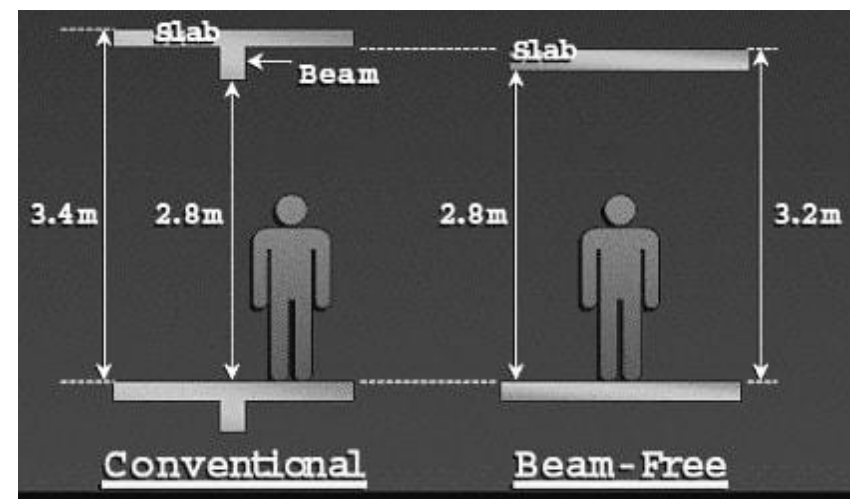

Figure 1: Comparison of conventional slab and flat slab

Stiffness of floor, natural frequency and damping capacity has been changed to reduce the problems on vibrations which cause residents to feel anxious and uncomfortable. Even if a building is safe, people can feel anxious when the building vibrates. Thickness of flat slab is very attractive benefit because thin slab provides the advantage of increased floor to ceiling height and lower cladding cost for the owner. However, there is profound lower limit to thickness of slab because extra reinforcements are needed to tackle design issues.

\section{Literature Review}

Seismic response of flat slab building has been a subject of discussion since many decades. The literature shows the considerable working and study on flat slab buildings and its behavior under seismic excitation. Some of related works are discussed below:

R.P Apostolska, et al. "1] "Seismic performance of flat slab building structural systems". The paper shows that the purely flat slab RC structural system is considerably more flexible for horizontal loads than the traditional RC frame structures, which contribute to the increase of vulnerability to seismic effects. The critical moment in the design of these systems is the slab- column system. To increase the bearing capacity of the flat slab structure, under horizontal loads, particularly when speaking about seismically prone areas and limitation of deformations, modifications of the system by adding structural elements are necessary. Modifications with additional construction elements improve small bearing capacity of the system and increase strength and stiffness, improving seismic behaviour of flat slab construction system.

K. S. Sable et al. ${ }^{[2]}$ compared the seismic behavior of multistoried flat slab building and conventional reinforced concrete framed structure. Zone II was considered for the analysis. The author concluded that natural time period will increase as the height of structure increases for both but it will be same if they are provided with shear wall. The flat slab structure has more story drift then that of conventional RCC building.

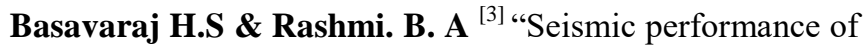
RC flat slab building structural systems" The paper shows that the fundamental natural period of the building decreases with increase in storey stiffness due to the presence of shear walls and infill walls. High rise flat slab buildings which are vulnerable to lateral loads, must need shear walls to reduce 


\section{International Journal of Science and Research (IJSR) \\ ISSN (Online): 2319-7064 \\ Index Copernicus Value (2015): 78.96 | Impact Factor (2015): 6.391}

lateral deflection and inter storey drift. If it is properly oriented, it will reduce the storey deflection.

\section{Methodology}

Slab Panel Model for the Parametrical Analysis:

Slab thickness

$100 \mathrm{~mm}$

to

$250 \mathrm{~mm}$

Dimension

Characteristic compressive strength

$10 \mathrm{~m} \times 8 \mathrm{~m}$

Poisson ratio

$30 \mathrm{Mpa}$

Live load

$3.5 \mathrm{KN} / \mathrm{m}^{2}$

\begin{tabular}{c}
$\begin{array}{c}\text { Flat Slab Panel } \\
10 \mathrm{~m} \times 8 \mathrm{~m}\end{array}$ \\
\hline
\end{tabular}

Figure 2: Flat slab model

Determining vibration characteristics requires finding the natural frequency of a floor system. The parameters to use for the computation of the first natural frequency of rectangular slab panels with different boundary conditions are explained below

$$
\mathrm{f}=\frac{\mathrm{c}}{\mathrm{a}^{2}} \varphi
$$

Where

$$
c=\sqrt{\frac{E h^{3}}{12\left(1-v^{2}\right)} \times \frac{g}{q}}
$$

$\mathrm{f}=$ first natural frequency

$\mathrm{a}=$ span length in X-direction

$\mathrm{E}=$ dynamic modulus of elasticity

$\mathrm{h}=$ slab thickness

$v=$ Poisson's ratio

$\mathrm{g}=$ gravitational acceleration

$q=$ weight per unit surface area of the slab.

Table 1: First Natural Frequency Constant $\Phi$ for

\begin{tabular}{|c|c|c|}
\hline S.No. & $\begin{array}{l}\text { Boundary } \\
\text { Conditions }\end{array}$ & Constant $\Phi$ \\
\hline 1 & & $\Phi=1.57\left(1+\gamma^{2}\right)$ \\
\hline 2 & & $\Phi=1.57 \sqrt{1+2.5 \gamma^{2}+5.14 \gamma^{4}}$ \\
\hline 3 & & $\Phi=1.57 \sqrt{5.14+2.9 Y^{2}+2.44 Y^{4}}$ \\
\hline 4 & & $\Phi=1.57 \sqrt{1+2.33 \gamma^{2}+2.44 \gamma^{4}}$ \\
\hline 5 & & $\Phi=1.57 \sqrt{2.44+2.72 \gamma^{2}+2.44 \gamma^{4}}$ \\
\hline 6 & & $\Phi=1.57 \sqrt{5.14+3.13 \gamma^{2}+5.14 \gamma^{4}}$ \\
\hline
\end{tabular}
Rectangular Slab Panels of Uniform Thickness, as in [5]

Notations:

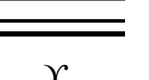

Rigidly Supported and Rotationally Free

r Rigidly Supported and Rotationally Fixed Span/Width ratio

\section{Results}

Following few results have been shown which are obtained from the dynamic analysis of the flat slab model. The frequency ratios $\left(\omega_{\mathrm{n}}-\omega_{\mathrm{d}}\right)$ determined for different damping ratios and thickness of slab while changing the support cases are obtained by considering the system as free undamped and free damped system.

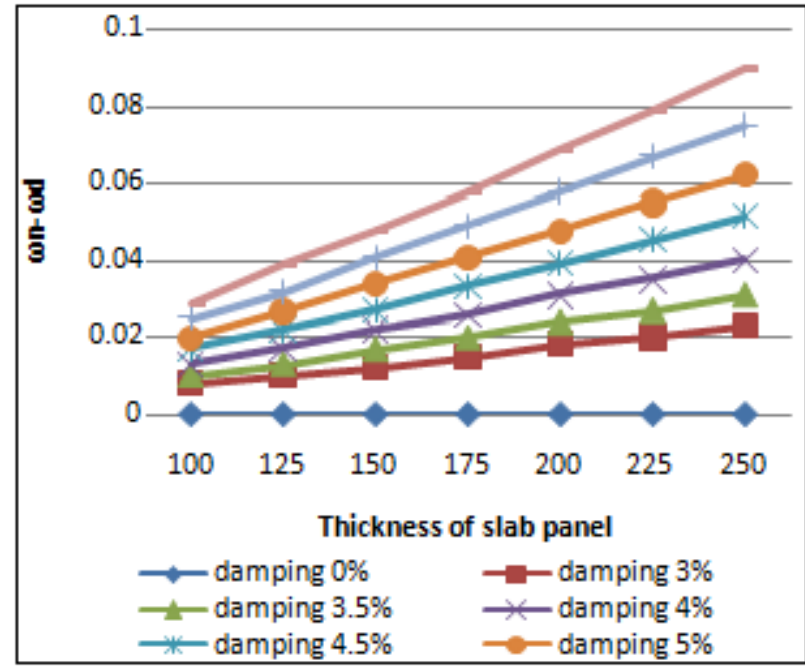

Figure 3: Frequency content v/s thickness of slab for support case 1

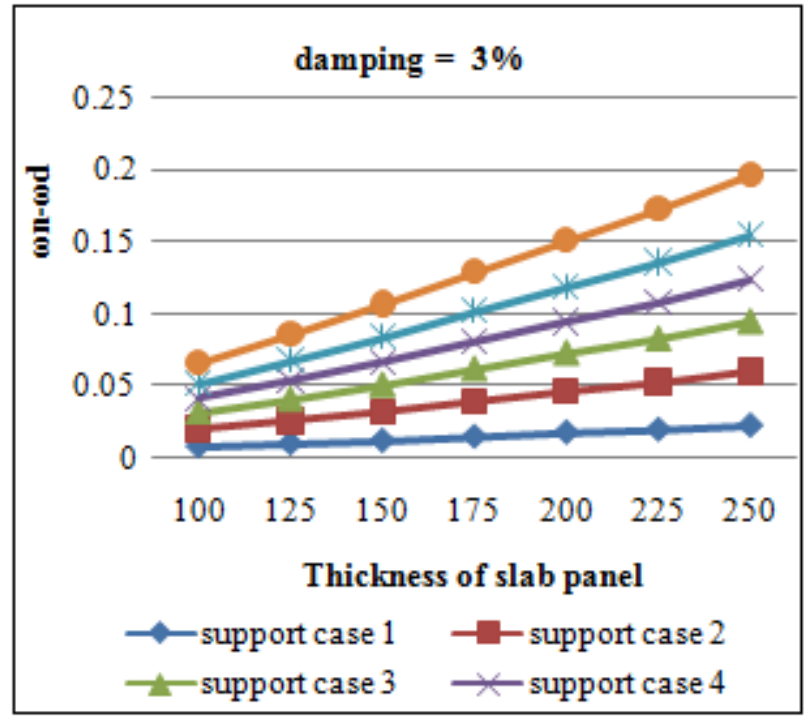

Figure 4: Comparison of frequency content and support cases at $3 \%$ damping ratio

The below graphs are obtained by taking the forced undamped vibrations into considerations. Response of different exciting frequencies $(\omega)$ upon the flat slab under different support cases is obtained by using below equation, as the initial conditions are taken as zero.

$$
u(t)=\frac{p_{o}}{k} \frac{1}{1-\left(\omega / \omega_{n}\right)^{2}}\left(\sin \omega t-\frac{\omega}{\omega_{n}} \sin \omega_{n} t\right)
$$

The graphs show that as time increases, amplitude (displacement) of vibration $x(t)$ also increases which is unsafe. That means, the slab takes more time to come back to its original position and is therefore required to be controlled. 


\section{International Journal of Science and Research (IJSR) \\ ISSN (Online): 2319-7064 \\ Index Copernicus Value (2015): 78.96 | Impact Factor (2015): 6.391}

It study also shows that as depth of the flat slab increases, $x(t)$ tends to decrease. That means deflection in flat slab decreases, which contributes towards the safer side. Angular frequency also increases with the increase in the depth of flat slab and thus needs to be controlled.

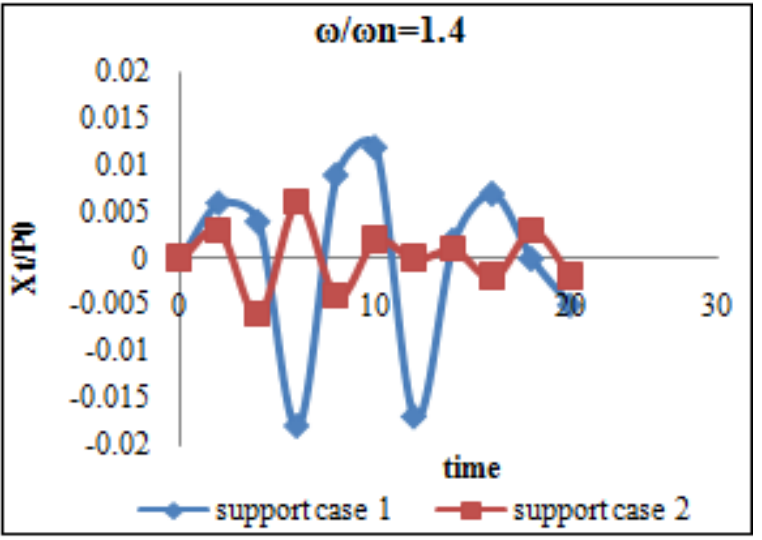

Figure 5: Comparison of Response of two support cases of flat slab at $\omega / \omega_{\mathrm{n}}=1.4$ at thickness $250 \mathrm{~mm}$

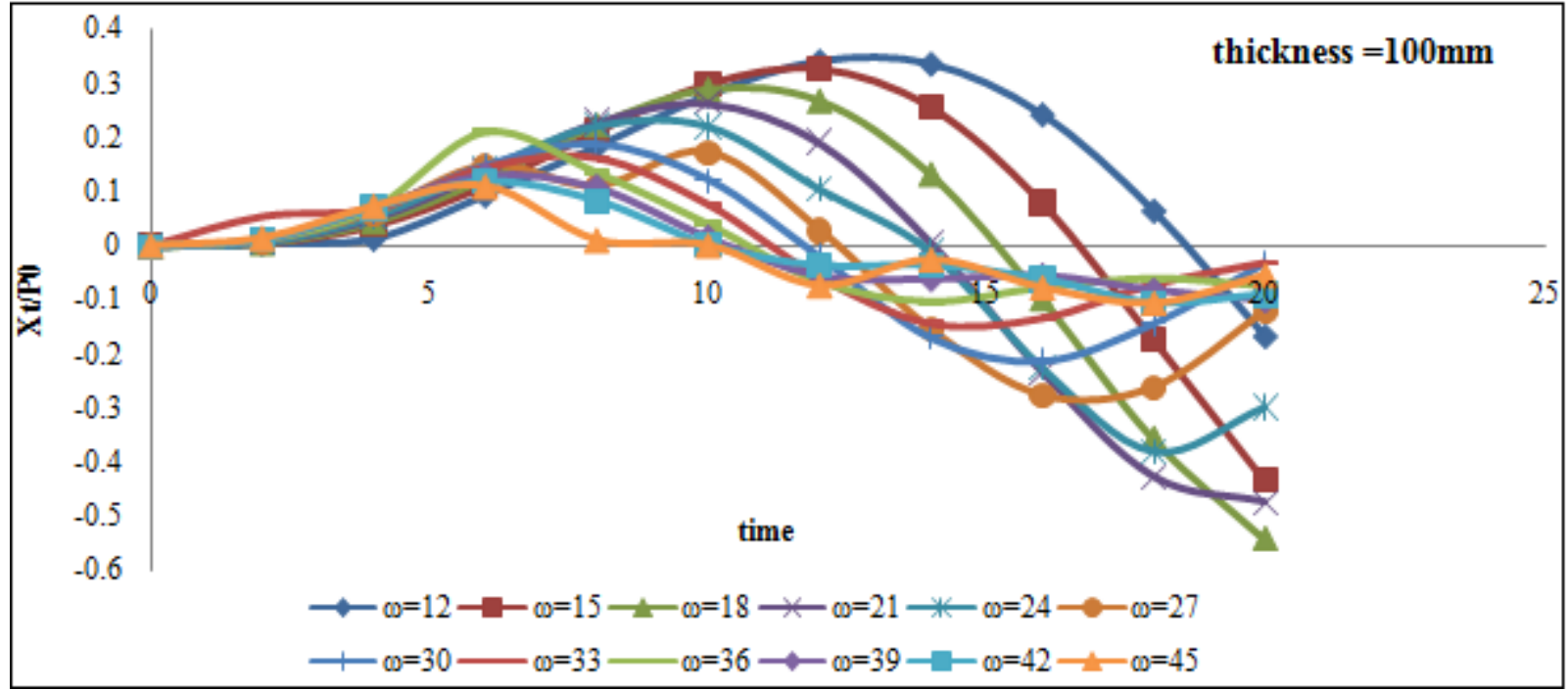

Figure 6: Response of flat slab panel under different forcing frequencies at 100mm depth for support case 1

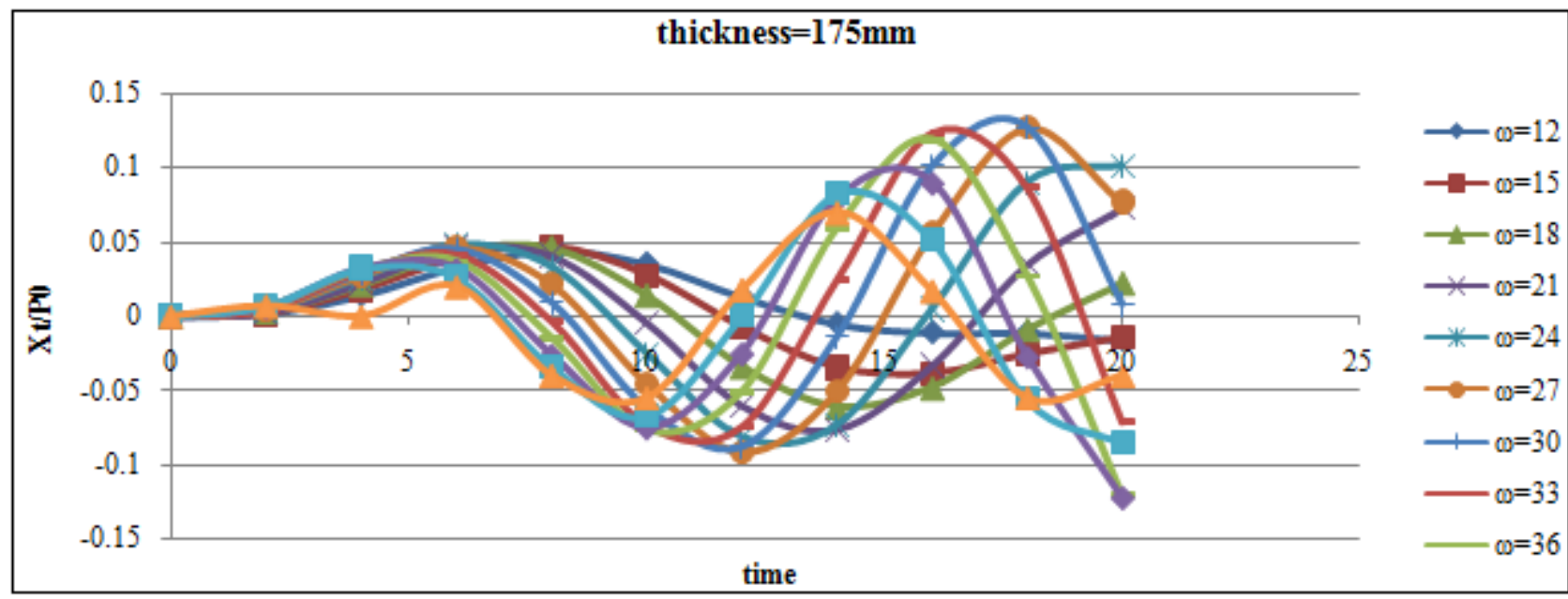

Figure 7: Response of flat slab panel under different forcing frequencies at $175 \mathrm{~mm}$ depth for support case 1

\section{Conclusions}

Since the thickness of slabs is very less, therefore, they vibrate when dynamic load is applied on them. These vibrations are function of span, width, thickness and the material characteristics of the slab. The excessive vibrations are transmitted to other parts of the building and may result in the overall damage of the structure, household, articles/items, and also with fear psychosis. The study obtained optimum parameters in order to control the deflections and vibrations of slab in buildings and thus the following conclusions were drawn:

\section{Volume 6 Issue 6, June 2017 www.ijsr.net}




\section{International Journal of Science and Research (IJSR) \\ ISSN (Online): 2319-7064}

Index Copernicus Value (2015): 78.96 | Impact Factor (2015): 6.391

(a) As time increases, amplitude (deflection) of vibration $X_{t}$ also increases and therefore the slab will take sufficient time to restore its original position and hence affecting the structural stability of flat slab. This parameter needs to be considered while designing the slabs.

(b) Therefore more the rigidity of slab panel, higher will be its frequency of vibrations and may create fear psychosis to the users. To avoid unwanted frequency of vibrations, desired flexibility can be incorporated in slabs through support conditions. Partially restrained supports are helpful in this case

(c) For short duration of vibrations, the frequency ratio $\left(\omega / \omega_{n}\right)$ more than 1 is advantageous as the deflection is lesser than when the frequency ratio is lesser than 1 .

(d) When the damping is increased, the difference in frequency content $\omega_{\mathrm{n}}-\omega_{\mathrm{d}}$ also increases. It indicates higher the damping ratio; lower will be the damped frequency of vibration of a given slab. Therefore together with the support conditions, damping plays a vital role in controlling the vibration of the floors.

\section{Future Scope}

The research work has been carried out on the undamped forced vibrations of flat slabs only as the cases with very less damping are considered as undamped. So this work can further be extended to damped forced vibrations of flat slabs where the damping can be brought to the structure either by using damping materials or because of dampers.

\section{References}

[1] Apostolska R.P, Necevska G.S -Cvetanovska, Cvetanovska J.P and Mircic.N "Seismic performance of flat slab building structural systems", The $14^{\text {th }}$ Conference onEearthquake Engineering, 2008,Beijing, China

[2] Sable. K.S, Ghodechor V.A,B. Kandekar S.B, "Comparative study of seismic behavior of multi story flat slab and conventional reinforced concrete framed structures", Internaional Journal of Computer Technology and Electronics Engineering, Vol 2, Issue 3, June 2012.

[3] Basavaraj H.S \& Rashmi.B.A "Seismic performance of RC flat slab building structural systems" International Journal of Informative and Futuristic Research. Vol 2, Issue 9, May 2015. ISSN:2347-1697

[4] Chopra, Anil K, "Dynamics of Structures" University of California at Berkeley Prentice Hall, Englewood Cliffs, New Jersey 07632

[5] Vibration Design of Floors- Guideline, STB RWTH Aachen 2008

[6] Makode, K.R., Akhtar, S., Batham, G.,"Dynamic analysis of multistory rcc building frame With flat slab and grid slab", al Int. Journal of Engineering Research and Applications, Vol. 4, Issue 2(Version 1), February 2014, pp.416-420.

[7] More R. S , Sawant V. S , Suryawanshi Y. R , "Analytical Study of Different Types of Flat Slab Subjected to Dynamic Loading" -International Journal of Science and Research (IJSR) ISSN : 2319-7064

[8] Aggarwal P. and Shrikhande M.- "Earthquake Resistant Design Of Structures", Prentice -Hall Publications
[9] Navyashree k, Sahana, "Use of flat slabs in multi-storey commercial building situated in high seismic zone volume": 03 issue: 08 | aug-2014

[10] Gupta B. L. and Gupta .A, "Principles of Earthquake Resistant Design of Structures and Tsunami", New Delhi, 2013 